\title{
An assessment of the impact of ATMS and CrIS data assimilation on precipitation prediction over the Tibetan Plateau
}

\author{
Tong Xue ${ }^{1,2,4,5}$, Jianjun $\mathrm{Xu}^{2,3}$, Zhaoyong Guan ${ }^{1}$, Han-Ching Chen ${ }^{5,6}$, Long S. Chiu ${ }^{5}$, and Min Shao ${ }^{7}$ \\ ${ }^{1}$ Key Laboratory of China Education Ministry for Meteorological Disasters, Nanjing University of Information Science \\ and Technology, Nanjing, China \\ ${ }^{2}$ Guangdong Ocean University, Zhanjiang, China \\ ${ }^{3}$ State Key Laboratory of Severe Weather, Chinese Academy of Meteorological Sciences, China \\ ${ }^{4}$ China Meteorological Administration Training Centre, Beijing, China \\ ${ }^{5}$ AOES, College of Science, George Mason University, Fairfax, Virginia, USA \\ ${ }^{6}$ Department of Atmospheric Sciences, National Taiwan University, Taipei, Taiwan \\ ${ }^{7}$ GENRI, College of Science, George Mason University, Fairfax, Virginia, USA
}

Correspondence to: Jianjun Xu (gdouxujj@qq.com) and Han-Ching Chen (s910810909@gmail.com)

Received: 31 January 2017 - Discussion started: 27 February 2017

Revised: 7 June 2017 - Accepted: 16 June 2017 - Published: 19 July 2017

\begin{abstract}
Using the National Oceanic and Atmospheric Administration's Gridpoint Statistical Interpolation data assimilation system and the National Center for Atmospheric Research's Advanced Research Weather Research and Forecasting (WRF-ARW) regional model, the impact of assimilating Advanced Technology Microwave Sounder (ATMS) and Cross-track Infrared Sounder (CrIS) satellite data on precipitation prediction over the Tibetan Plateau in July 2015 was evaluated. Four experiments were designed: a control experiment and three data assimilation experiments with different data sets injected: conventional data only, a combination of conventional and ATMS satellite data, and a combination of conventional and CrIS satellite data. The results showed that the monthly mean of precipitation is shifted northward in the simulations and showed an orographic bias described as an overestimation upwind of the mountains and an underestimation in the south of the rain belt. The rain shadow mainly influenced prediction of the quantity of precipitation, although the main rainfall pattern was well simulated. For the first $24 \mathrm{~h}$ and last $24 \mathrm{~h}$ of accumulated daily precipitation, the model generally overestimated the amount of precipitation, but it was underestimated in the heavy-rainfall periods of 3-5, 13-16, and 22-25 July. The observed water vapor conveyance from the southeastern Tibetan Plateau was larger than in the model simulations, which induced inaccuracies in the forecast of heavy rain on 3-5 July. The data assimilation
\end{abstract}

experiments, particularly the ATMS assimilation, were closer to the observations for the heavy-rainfall process than the control. Overall, based on the experiments in July 2015, the satellite data assimilation improved to some extent the prediction of the precipitation pattern over the Tibetan Plateau, although the simulation of the rain belt without data assimilation shows the regional shifting.

\section{Introduction}

The Tibetan Plateau (TP) is the highest and largest plateau in the world. It is located on the central Eurasian continent, stands in the middle troposphere, and covers an area of approximately 2.5 million $\mathrm{km}^{2}$. The TP has a variety of topographical features of a large terrain gradient, and its steep mountains are aligned with an east-to-west arrangement. The dramatic modification caused by the rugged terrain influences the local atmospheric circulation and causes strong local convection to arise, easily inducing severe weather such as heavy rainfall, windstorms, and hailstorms (Massacand et al., 1998; Gao et al., 2015). Precipitation is one of the key variables for understanding the hydrological cycle on the TP and has profound effects on the regional and global circulation that affect millions of people in the adjacent areas (Ye and Gao, 1979; Chen et al., 1985; Chambon et al., 2014). 
Therefore, making accurate and long-lead weather forecasts at high temporal and spatial resolution for the TP not only has scientific significance but also addresses the urgent need for disaster prevention. However, due to the variable weather conditions and complex terrain orography, the TP remains a sparsely populated region with few conventional observation data sources, and the limited amount of available meteorological data leads to great uncertainties in the regional weather forecasts. The continuous development of numerical weather prediction (NWP) models, such as the National Center for Atmospheric Research (NCAR)'s Advanced Research Weather and Research Forecasting (WRF-ARW) model, offers opportunities to improve regional weather forecasts in data-sparse regions. NWP models can be initialized with and laterally assimilate observation data, which is beneficial for better describing atmospheric conditions, thus keeping model results close to observations (Maussion et al., 2011).

Satellite radiance data are one of the most important observation data sources and can be directly assimilated into data assimilation (DA) models. Compared with conventional observation data, geostationary satellite data have continuous spatial and temporal coverage, and polar-orbiting satellites circle the Earth twice a day to provide global observations of multiple meteorological variables, such as temperature, pressure, and moisture. Moreover, many studies have suggested that the assimilation of satellite radiance data can substantially improve weather forecasts (Eyre, 1992; Derber and Wu, 1998; Xu et al., 2009). For longer-range prediction, satellite data are even more crucial than conventional observations (Zapotocny et al., 2008). Past studies have also indicated that the effect of assimilation of both observations and satellite products is better than only satellite data assimilation (Liu et al., 2013). However, the performance of satellite radiance assimilation in limited-area modeling systems using variational DA method is still controversial (Zou et al., 2013; Newman et al., 2015). Schwartz et al. (2012) were the first to assimilate microwave radiances in a region lacking observation stations using the ensemble Kalman filter (EnKF), and the results showed that assimilating microwave radiances overall produced better forecasts of Typhoon Morakot (2009). The negative influence has also appeared, and it is mainly contributed to various of factors such as the influence of lateral boundary conditions within the regional domain (Warner et al., 1997) and non-uniform satellite coverage (Kazumori et al., 2014).

The Advanced Technology Microwave Sounder (ATMS) and Cross-track Infrared Sounder (CrIS) are two instruments with high resolution on board the Suomi National Polar-orbiting Partnership spacecraft, a polar-orbiting satellite launched in 2011 with the aim to provide real-time sensor data for critical weather and climate measurements. The ATMS, a cross-track microwave scanner with 22 channels, combines most of the channels of the preceding Advanced Microwave Sounding Unit (AMSU-A) and Microwave Humidity Sounder (MHS) to provide sounding profiles of at- mospheric moisture and temperature. The CrIS is a Fourier transform spectrometer with 1305 spectral channels inherited from the High-Resolution Infrared Radiation Sounder (HIRS) to produce temperature, pressure, and moisture profiles. A previous study assimilated ATMS data in the European Centre for Medium-Range Weather Forecasts system, and the results showed that the instrument had better performance than AMSU-A and MHS in the longer range over the Northern Hemisphere (Bormann et al., 2013). Nevertheless, satellite data assimilation into NWP models over the TP presents special challenges, because the limited model capability for assimilating radiance data over complex terrain with heterogeneous characteristics is still not clearly recognized. Furthermore, whether the new generation of satellite observations, such as ATMS and CrIS, can compensate for the shortage of data over the TP and effectively enhance the accuracy of forecasts remains unknown.

In this paper, we make an assessment of the impact of assimilating ATMS and CrIS radiance data for East Asia on precipitation prediction over the TP and compare the effects of different satellite data sets injected.

\section{Data and models}

\subsection{Data}

\subsubsection{Data used for the assimilation}

The conventional data, which are from the Global Data Assimilation System (GDAS)-prepared BUFR files (gdas1.tCCz.prepbufr.nr), are composed of a global set of surface and upper-air reports operationally collected by the National Centers for Environmental Prediction (NCEP). It includes radiosondes, surface ship and buoy observations, surface observations over land, pilot balloon (pibal) winds and aircraft reports from the Global Telecommunications System (GTS), profiler and US radar-derived winds, Special Sensor Microwave Imager (SSM/I) oceanic winds and atmospheric total column water (TCW) retrievals, and satellite wind data from the National Environmental Satellite Data and Information Service (NESDIS). The reports can include pressure, geopotential height, temperature, dew point temperature, and wind direction and speed (National Centers for Environmental Prediction/National Weather Service/NOAA/US Department of Commerce, 2008).

\subsubsection{Data used for the evaluation/verification}

Observational precipitation data from the National Meteorological Information Center (NMIC) of the China Meteorological Administration (CMA) was used as the truth data for comparison with the model results. The $0.1^{\circ} \times 0.1^{\circ}$ highresolution gridded hourly China Merged Precipitation Analysis (CMPA) data gauge, which combines the CMA's rain gauge hourly data provided by more than 30000 automatic 
weather stations with the National Oceanic and Atmospheric Administration (NOAA) Climate Prediction Center's Morphing (CMORPH) precipitation product (Xie and Xiong, 2011; Pan et al., 2012; Shen et al., 2014), was used for verification to evaluate the model simulation results. Considering the topographically complex terrain characterizing the $\mathrm{TP}$, satellite precipitation data with very high spatial resolution are especially needed. The CMORPH product makes use of the precipitation estimate techniques that have been derived from low-orbit satellite microwave observations and geostationary satellite infrared (IR) data with spatial propagation features. Several studies (Gao and Liu, 2013; Guo et al., 2014; Tong et al., 2014; Zhang et al., 2015) have compared the CMORPH data with satellite precipitation data sets in the TP area with the conclusion that CMORPH is one of the most suitable products to use in studying precipitation over the TP. During the period from May to October 2004-2009, Tropical Rainfall Measuring Mission (TRMM) Multisatellite Precipitation Analysis real-time research 3B42 version 6 (TMPA) and CMORPH show better performance with higher correlation and lower root mean square error (RMSE) than the Precipitation Estimation from Remotely Sensed Information using Artificial Neural Network (PERSIANN) and TMPA's real time version (TMPART) over the TP (Gao and Liu, 2013). Of the several merged satellite precipitation products (i.e., TMPA; PERSIANN; and the Global Satellite Mapping of Precipitation, GSMaP), the CMORPH product with the highest resolution $(8 \mathrm{~km})$ can capture the afternoon-to-evening precipitation pattern (Guo et al., 2014). Tong et al. (2014) has also compared the performance of four widely used high-resolution satellite precipitation estimates against gauge observations (the CMA data) over the TP during January 2006-December 2012. It is worth noticing that TMPA and CMORPH data had better performance in depicting precipitation timing and amount than the TMPART and PERSIANN at both the plateau and basin scale. Zhang et al. (2015) has also come to the conclusion that the highresolution CMORPH data can depict finer regional details, such as a less coherent phase pattern over the TP, and better capture the features of the diurnal cycle of summer precipitation than TRMM 3B42.

NCEP Final Analysis (FNL) data were used through dynamic downscaling as observed moisture to illustrate the transportation of water vapor in East Asia.

\subsubsection{Radiance data quality control}

As the quality of the observational data is easily affected by the observation instruments, station positions, or human factors, carrying out quality control (QC) before data application is necessary (Hubbard and You, 2005). Before data assimilation, a multiple-step QC procedure was applied to the satellite radiance data in the Gridpoint Statistical Interpolation (GSI) system and preprocessed by NOAA's National Environmental Satellite Data and Information Service (NES-
Table 1. The channels for ATMS and CrIS data that have been selected for the data assimilation procedure.

\begin{tabular}{ll}
\hline Sensor & Channels \\
\hline ATMS & $1-14,16-22$ \\
CrIS & $37,49,51,53,59,61,63,65,67,69,71,73,75$, \\
& $77,79,80,81,83,85,87,89,93,95,96,99,101$, \\
& $102,104,106,107,116,120,123,124,125$, \\
& $126,130,132,133,136,137,138,142,143$, \\
& $144,145,147,148,150,151,153,154,155$, \\
& $157-168,170,171,173,175,198,211,224$, \\
& $279,342,392,404,427,464,482,501,529$ \\
\hline
\end{tabular}

DIS). Besides data thinning, it can be summarized in several QC categories in GSI to either discard the questionable observations or inflate the low-confidence observations. The detailed quality control can be found in section 8.3 ("Radiance observation quality control") in the GSI Advanced User's Guide version 3.5 by Developmental Testbed Center (DTC) (2016). The observational number of ATMS data ranging from 53042 to 68618 in contrast to the number of CrIS data ranging from 2694048 to 3454542 was read in the DA system. After the data had passed rigorous quality assessment and quality control processes, the results showed that about 23.2-26.4, 1.3, and 1.6\% of "good" observations related to ATMS- and CrIS-read data were separately retained after quality control (Fig. 2). This difference can be explained as follows: CrIS has 1305 channels of satellite radiance data, but the number of assimilated channels is significantly reduced (Table 1), the selection of redundant channel leads to some part of observation radiance data coming from a similar altitude, and it contains large amount of repeated information. Therefore, a larger percentage of CrIS satellite radiance data than ATMS is discarded through QC steps. Figure $1 \mathrm{~b}$ shows the distribution of the conventional data at 06:00 UTC on 1 July 2015, where observational data are rare in the TP. Figure 1c and d display the distribution of satellite data after quality control, where there is almost complete spatial coverage in East Asia, including the TP. 

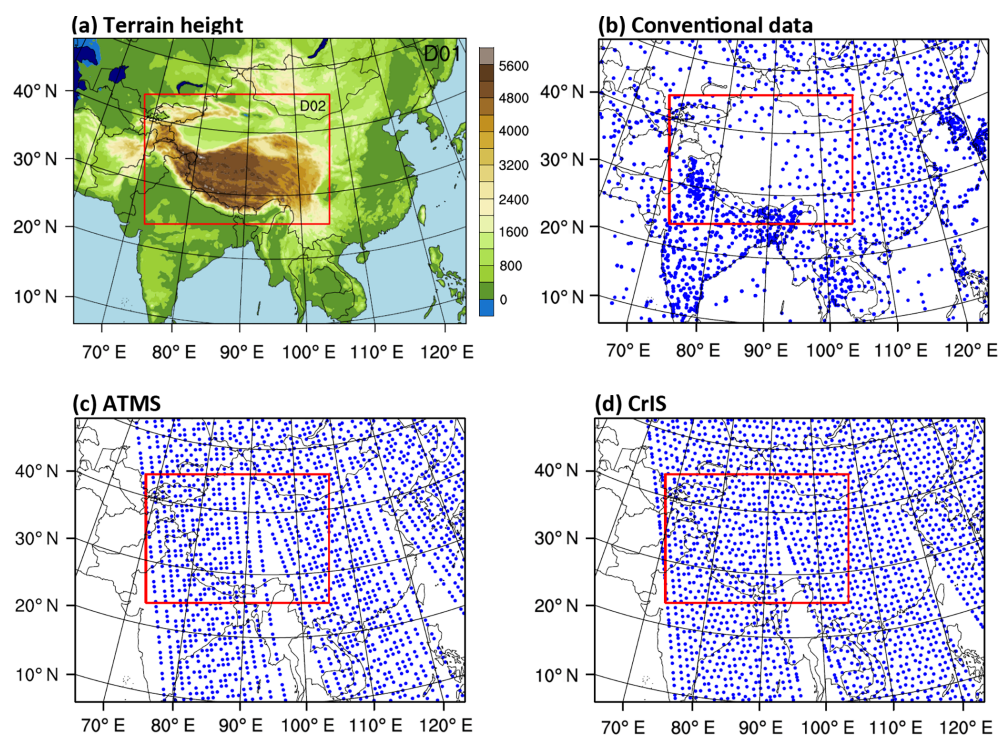

Figure 1. (a) Simulation domains and topography. Resolutions are at 12 and $4 \mathrm{~km}$ for the outer (coarse grid, D01) and inner (nested grid, D02) boxes, respectively. The shading indicates the terrain elevation (unit: $\mathrm{m}$ ). (b-d) Distribution of (b) conventional data observations, (c) scan coverage of ATMS data after data assimilation, and (d) scan coverage of CrIS data after data assimilation at 06:00 UTC on 1 July 2015 .

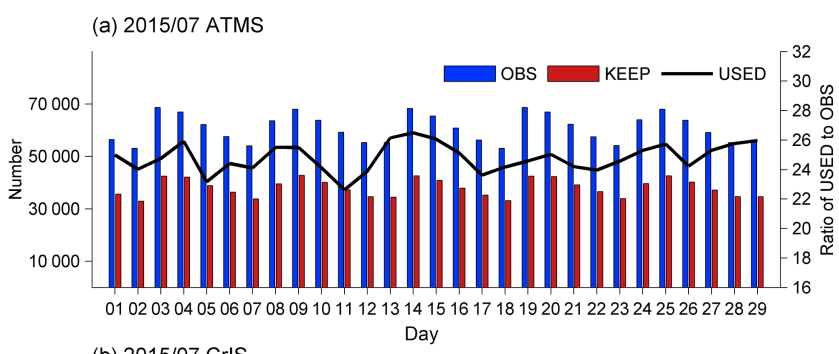

(b) $2015 / 07 \mathrm{CrIS}$

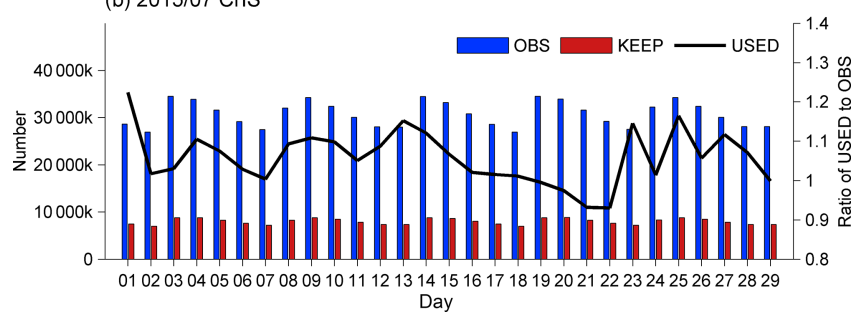

Figure 2. Blue bars indicate the total amount of radiance read in the DA system. Red bars present the number of kept radiance after first step of quality control. The percentage used after final quality control is shown as black curves. The right $y$ axis indicates the ratio of used amount to read amount, and the ratio is expressed as percent. (a) is for ATMS, and (b) is for CrIS data .

\subsection{Models}

\subsubsection{WRF-ARW regional model}

NCAR's WRF-ARW regional model associated with the GSI data assimilation system was used in this study. WRF-ARW is a fully compressible nonhydrostatic, primitive-equation, mesoscale meteorological model. As shown in Fig. 1a, the model domains are two-way nested with $12 \mathrm{~km}(580 \times 422)$ and $4 \mathrm{~km}(817 \times 574)$ horizontal spacing. There are 51 vertical levels with a model top of $10 \mathrm{hPa}$. Figure 1 shows that D01 is set to cover most of East Asia, and the subdomain (D02) inside corresponds to the Tibetan Plateau, which has a mountain-valley structure.

The physical parameterizations chosen for the forecast model in this study followed previous studies of the area (He et al., 2012; Jianyu Xu et al., 2012; Zhu et al., 2014). These included the WRF-ARW Single-Moment 6-class (WSM-6) microphysics scheme, the Kain-Fritsh (KF) cumulus parameterization, the Rapid Radiative Transfer Model (RRTMG) longwave and shortwave radiation, the Yonsei University scheme (YSU), and the Noah Land Surface Model for the planetary boundary layer scheme.

The NCEP Global Forecast System (GFS) forecast data, which has a horizontal resolution of $0.5^{\circ} \times 0.5^{\circ}$ with a $6 \mathrm{~h}$ interval, were used as the boundary and initial conditions for the control (CTRL) experiment, while the background fields of DA experiments take advantage of the forecast product at 06:00 UTC made by CTRL. The GFS data are publicly available at https://www.ncdc.noaa.gov/data-access/model-data/ model-datasets/global-forcast-system-gfs.

\subsubsection{The GSI 3D-Var system and Community Radiative Transfer Model}

In this study, we chose to use the GSI 3D-Var system, which is a data assimilation system that was initially developed as the next-generation analysis system based on the operational 
Spectral Statistical Interpolation (SSI) at NCEP (Derber and Wu, 1998).

Instead of the spectral definition of background errors in the SSI, GSI is constructed in physical space, where the background errors can be represented by a non-homogeneous and anisotropic grid point and used for both global and regional forecasts. GSI utilizes recursive filters and is designed to be a flexible system that is efficient on available parallel computing platforms (Wu et al., 2002; Purser et al., 2003a, b). The GSI 3D-Var system provides an optimal analysis through two steps of outer iterative minimization of a prescribed function as follows:

$$
\begin{aligned}
J & =\frac{1}{2}\left(x_{\mathrm{a}}-x_{\mathrm{b}}\right)^{\mathrm{T}} B^{-1}\left(x_{\mathrm{a}}-x_{\mathrm{b}}\right) \\
& +\frac{1}{2}\left(H(x)-O_{\mathrm{o}}\right)^{\mathrm{T}} O^{-1}\left(H(x)-O_{\mathrm{o}}\right),
\end{aligned}
$$

where $x_{\mathrm{a}}$ is the analysis state and can be calculated by minimizing the penalty function $J ; x_{\mathrm{b}}$ is the first guess that comes from the GFS product in this article representing background model state; $O_{\mathrm{o}}$ are the observations including conventional observation, satellite radiance data, radar data, etc.; and $H(x)$ is the transformation operator from the analysis variable to the form of the $O_{\mathrm{o}}$ error. By means of the two sources of a priori data - the first guess $x_{\mathrm{b}}$ and the observations $O_{\mathrm{o}}-$ the solution for the penalty function which indicates the a posteriori maximum-likelihood estimate of the true atmospheric state can be found. $B$ and $O$ are the error estimates of $x_{\mathrm{b}}$ (covariance matrix of the background error) and $O_{\mathrm{o}}$ (covariance matrix of the observation error), respectively, which are used to weight the analysis fit to individual observations ( $\mathrm{Wu}$ et al., 2002).

The development of fast radiative transfer models has allowed for the direct assimilation of satellite infrared and microwave radiances in NWP systems (Saunders et al., 1999; Gauthier et al., 2007; Zou et al., 2011). The Community Radiative Transfer Model (CRTM) developed by the United States Joint Center for Satellite Data Assimilation (JCSDA) has been incorporated into the NCEP GSI system to rapidly calculate satellite radiances (Han et al., 2006; Weng, 2009). After ATMS and CrIS data are read into the GSI, simulated brightness temperature is calculated via CRTM 2.1.3 in this study. It is worth noticing that the CrIS scans a $2200 \mathrm{~km}$ swath width $\left( \pm 50^{\circ}\right)$, with 30 Earth-scene views. Each field consists of nine fields of view, arrayed as a $3 \times 3$ array of $14 \mathrm{~km}$ diameter spots (nadir spatial resolution) (https: //jointmission.gsfc.nasa.gov/cris.html). The ATMS scans a $2300 \mathrm{~km}$ swath width with 96 Earth-scene views. Channels 1-2 of the spatial resolution of ATMS at nadir are $75 \mathrm{~km}$, channels 3-6 are $32 \mathrm{~km}$, and channels $17-22$ are $16 \mathrm{~km}$ (Dong et al., 2014).
Table 2. Rain contingency table used in the verification studies. As a threshold, $6 \mathrm{mmday}^{-1}$ is chosen to separate rain from no-rain events.

\begin{tabular}{lll}
\hline Forecast & \multicolumn{2}{l}{ Observed } \\
\cline { 2 - 3 } & Yes & No \\
\hline Yes & Hits & False alarms \\
No & Misses & Correct rejections \\
\hline
\end{tabular}

\section{Method and experimental design}

\subsection{Method}

A basic two-by-two contingency table (Table 2) was generated to calculate the bias score (BIAS), fraction skill score (FSS), equitable threat score (ETS), probability of false detection (POFD), probability of detection (POD), and false alarm ratio (FAR).

The BIAS (range: $0-\infty$; perfect score: 1), which measures the ratio of the frequency of forecast events to the frequency of observed events, is defined as

BIAS $=\frac{\text { hits }+ \text { false alarms }}{\text { hits }+ \text { misses }}$.

The FSS (range: 0-1; perfect score: 1), introduced by Roberts and Lean (2008), is a neighborhood verification method. The FSS is defined as

$\mathrm{FSS}=1-\frac{\mathrm{FBS}}{\text { FBS }_{\mathrm{ref}}}$.

Fractions Brier score (FBS) is presented as

$\mathrm{FBS}=\frac{1}{N} \sum_{i=1}^{N}\left[F_{\mathrm{o}}-F_{\mathrm{f}}\right]^{2}$

where $N$ is the number of all grid points in the domain. $F_{\mathrm{o}}$ and $F_{\mathrm{f}}$ are the observation and forecast fractions of the sliding window at each grid point. The sliding window in this study is $100 \mathrm{~km}$ (25 grid points). The reference fractions Brier score $\left(\mathrm{FBS}_{\mathrm{ref}}\right)$ represent the largest possible FBS and is given as

$\mathrm{FBS}_{\mathrm{ref}}=\frac{1}{N}\left[\sum_{i=1}^{N} F_{\mathrm{o}}^{2}+\sum_{i=1}^{N} F_{\mathrm{f}}^{2}\right]$

The ETS (range: $-1 / 3$ to 1 ; perfect score: 1 ) computes the fraction of observed events that were correctly predicted:

$\mathrm{ETS}=\frac{\text { hits }-R}{\text { hits }+ \text { false alarms }+ \text { misses }-R}$,

where $R$ is the random forecast coefficient, given by

$R=\frac{(\text { hits }+ \text { false alarms })(\text { hits }+ \text { misses })}{(\text { hits }+ \text { false alarms }+ \text { misses }+ \text { correct rejections })}$. 
The POFD (range: 0-1; perfect score: 0) measures discrimination:

$\mathrm{POFD}=\frac{\text { false alarms }}{\text { false alarms }+ \text { correct rejections }}$.

Similar to the POFD, the POD (range: 0-1; perfect score: 1 ) shows the hits out of total observed events:

POD $=\frac{\text { hits }}{\text { hits }+ \text { misses }}$.

The FAR (range: 0-1; perfect score: 0 ) indicates the fraction of the predicted events that did not occur:

$\mathrm{FAR}=\frac{\text { false alarms }}{\text { hits }+ \text { false alarms }}$.

To compare the model simulation data with the observation data, the $4 \mathrm{~km}$ model grid was interpolated to observation data with a $0.1^{\circ} \times 0.1^{\circ}$ grid based on the linear interpolation method.

\subsection{Experimental design}

Four 1-month-long experiments were conducted (Fig. 3). The CTRL experiment was carried out first with an initial time of 00:00 UTC and made $54 \mathrm{~h}$ forecasts. The data assimilation was applied on the D01 region of the output from CTRL at 06:00 UTC. The DA experiments made use of the assimilated D01 and the D02 from the CTRL at 06:00 UTC as the initial condition and made a $48 \mathrm{~h}$ forecast for each day. Three DA experiments were performed with a time window of $3 \mathrm{~h}$ : (1) a conventional run (CONV) assimilating the conventional observation data only; (2) an ATMS radiance run (ATMS) adding the ATMS satellite radiance data to the CONV; and (3) a CrIS radiance run (CRIS) adding the CrIS satellite radiance data to the CONV.

The accumulated precipitation integrated from 6 to $30 \mathrm{~h}$ and 30 to $54 \mathrm{~h}$ is defined as the first $24 \mathrm{~h}$ accumulated (F24H) precipitation and last $24 \mathrm{~h}$ accumulated $(\mathrm{L} 24 \mathrm{H})$ precipitation, respectively.

\section{Results}

\subsection{Impact of DA on the spatial fields of precipitation forecast}

Figure 4 shows the spatial pattern of the monthly mean of $24 \mathrm{~h}$ accumulated precipitation in July 2015. Monthly mean precipitation exhibits a decreasing south-to-north gradient. The predicted precipitation in the central and northern parts of the TP, Qaidam Basin (90-99 E, 35-39 $\mathrm{N}$ ), Tarim Basin $\left(75-90^{\circ} \mathrm{E}, 37-42^{\circ} \mathrm{N}\right)$, and Junggar Basin $\left(80-90^{\circ} \mathrm{E}\right.$, 45$48^{\circ} \mathrm{N}$ ) was too low to be measured (Fig. 4a, c). It was found that monthly averaged $\mathrm{F} 24 \mathrm{H}$ precipitation ranged from 6.0 to $30.4 \mathrm{~mm} \mathrm{day}^{-1}$, while the monthly averaged L24H precipitation ranged from 6.0 to $29.5 \mathrm{~mm} \mathrm{day}^{-1}$. The rain shadow



Figure 3. Top panel shows the schematic of data assimilation configuration with 3D-Var. Bottom panel presents the experiment design. CTRL: control experiment without data assimilation for which the initial time is 00:00 UTC from 1 to $31 \mathrm{July}$; CONV: data assimilation with conventional data only; ATMS: data assimilation with conventional and ATMS data; CRIS: data assimilation with conventional and CrIS data. CONV, ATMS, and CRIS experiments all start at 06:00 UTC from 1 to 31 July.

along the Himalayas $\left(73-95^{\circ} \mathrm{E}, 27-35^{\circ} \mathrm{N}\right)$ was found in the spatial distribution of precipitation. Because Fig. $4 \mathrm{a}$ is for F24H, the first day calculated in Fig. 4a was during the period of 06:00 UTC on 1 July to 06:00 UTC on 2 July and finally ended in the period of 06:00 UTC on 29 July to 06:00 UTC on 30 July. Therefore the different values in Fig. 4a and c can be explained as follows: Fig. 4c shows the L24H observed monthly mean accumulated precipitation, the computing process of which is different on two days from that of Fig. 4a. The CTRL (Fig. 4b, d) mostly simulated the monthly mean rain belt distributed along the southern and southwestern margin of the plateau, between the Himalayas in the west and the Hengduan Mountains $\left(95-103^{\circ}\right.$ E, 24$32^{\circ} \mathrm{N}$ ) in the east. The difference between the model simulations and observations (Fig. 5) indicated that the CTRL simulation tends to overestimate precipitation, especially in the southern and southwestern margin along the rain belt where the altitude changes from 500 to $3000 \mathrm{~m}$. The results suggested that the WRF-ARW model has limitations in simulating the precipitation in mountainous areas, which is similar to the conclusion of previous studies (He et al., 2012; Jianyu Xu et al., 2012). Furthermore, we found that the precipitation is overestimated (colored red) upwind of the mountains along the southwestern margin. In contrast, the precipitation is underestimated in the south of the rain belt, leading to a north-south dipole structure. This pattern results in a northward migration of the rain belt in the simulations. The three DA experiments indicated that the assimilation of satellite radiance data cannot calibrate the rain shadow effect, and all experiments showed consistently gross overestimation pat- 
(a) F24H observation

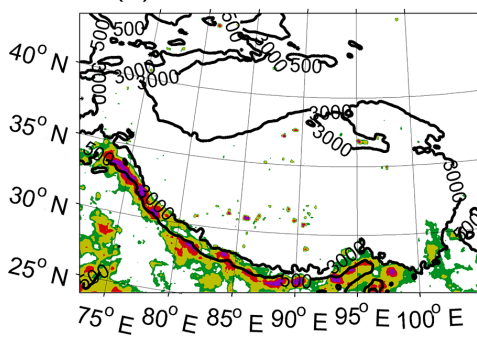

(c) L24H observation

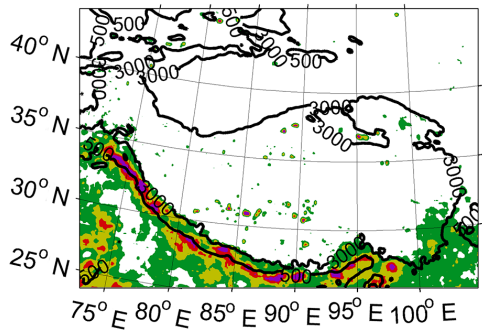

(b) F24H CTRL

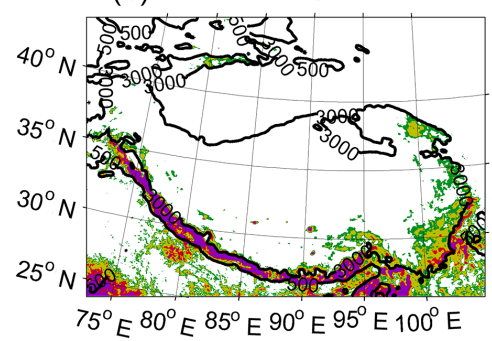

(d) L24H CTRL

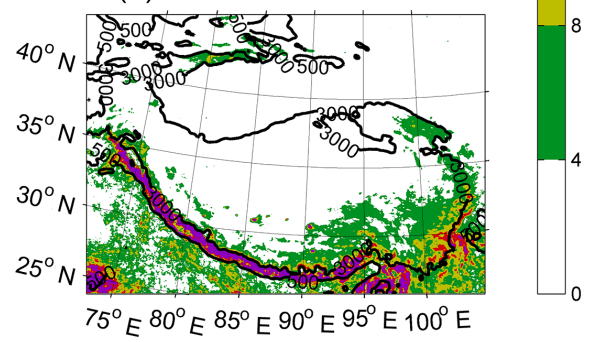

Figure 4. Daily precipitation averaged (unit: $\mathrm{mm}$ ) for the month of July 2015. (a, b) are F24H forecast, and (c, d) are L24H forecast. Black contours are altitude (unit: $\mathrm{m}$ ).

(a) F24H CTRL

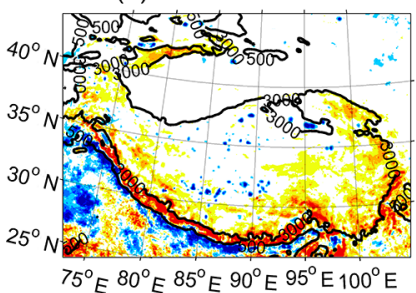

(e) L24H CTRL (b) F24H CONV

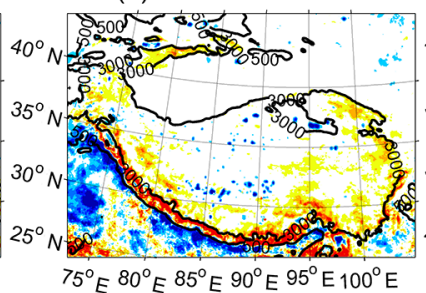

(f) L24H CONV (c) F24H ATMS

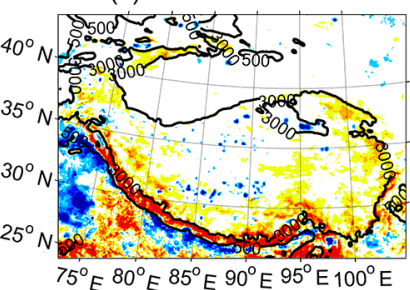

(g) L24H ATMS (d) F24H CRIS

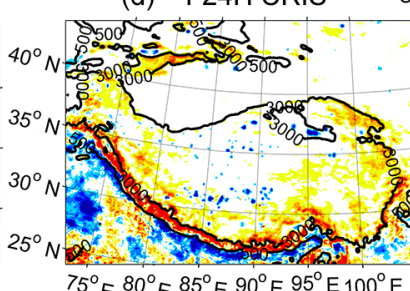

(h) L24H CRIS
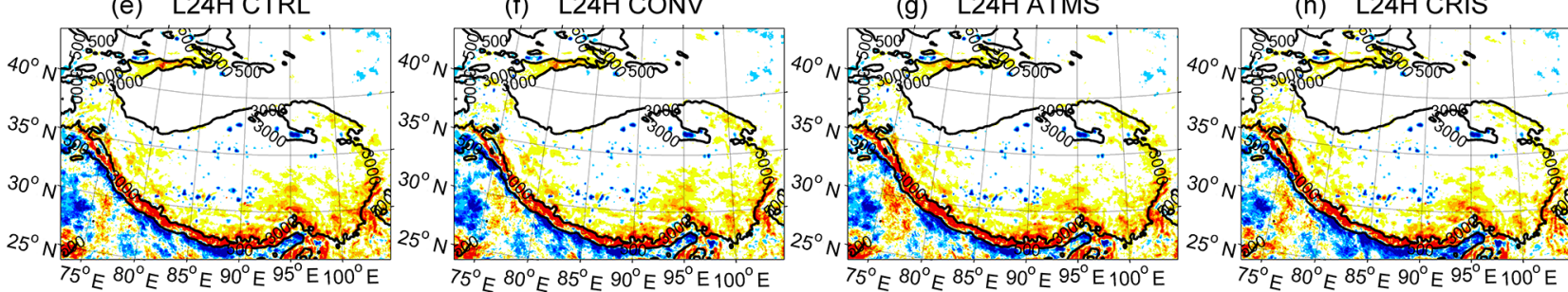

Unit: $\mathrm{mm}$

Figure 5. Difference value distribution of monthly mean precipitation (unit: mm) during July for data assimilation minus observation experiments. (a, e) CTRL minus OBS; (b, f) CONV minus OBS; (c, g) ATMS minus OBS; (d, h) CRIS minus OBS for (a-d) F24Hforecast and (e-h) L24Hforecast. Black contours are altitude (unit: $\mathrm{m}$ ).

terns, varying from 8 to $10 \mathrm{~mm}$ about the monthly mean daily precipitation. The overall bias statistic in D02 is $0.97 \mathrm{~mm}$ $(0.86 \mathrm{~mm}), 0.52 \mathrm{~mm}(0.70 \mathrm{~mm}), 1.08 \mathrm{~mm}(0.97 \mathrm{~mm})$, and $0.98 \mathrm{~mm}(0.76 \mathrm{~mm})$ for CTRL, CONV, ATMS, and CRIS, respectively. The values in brackets refer to $\mathrm{L} 24 \mathrm{~h}$. This may be attributed to the physical package of WRF-ARW having an inadequate description of snow cover over the plateau surface, making the error of margin more prominent (Marteau et al., 2015).

Figure 6 shows the spatial patterns according to the contingency table (Table 2) and the scatterplots, in which monthly mean $24 \mathrm{~h}$ rainfall over the $6 \mathrm{~mm} \mathrm{day}^{-1}$ threshold is defined as an "event". Rainfall events occur over most of the TP area, including the northern Gangetic Plain $\left(80-90^{\circ}\right.$ E, $\left.24-28^{\circ} \mathrm{N}\right)$ where the elevation is lower than $3000 \mathrm{~m}$, and can be well predicted with $\sim 8-10 \%$ hits (A) and $\sim 76-79 \%$ correct rejections (D) in the majority of the region. The false alarms (B) were spread mainly in the east of the TP, where the Bayan Har $\left(95^{\circ} \mathrm{E}, 35^{\circ} \mathrm{N}\right)$ and Hengduan mountains are located, accounting for $\sim 7-10 \%$, while the misses (C) were distributed in the western plain outside of the TP and accounted for $\sim 5-$ $6 \%$. A dipole pattern is also evident in the distribution of 
(a) F24H CTRL

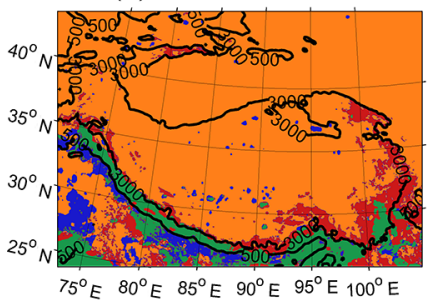

(e) F24H CTRL

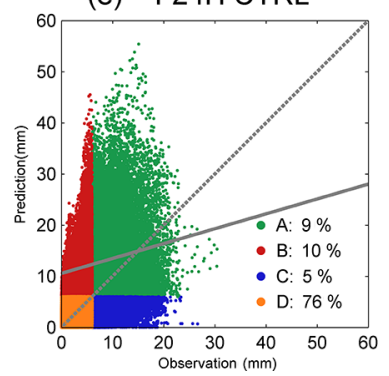

(b) F24H CONV

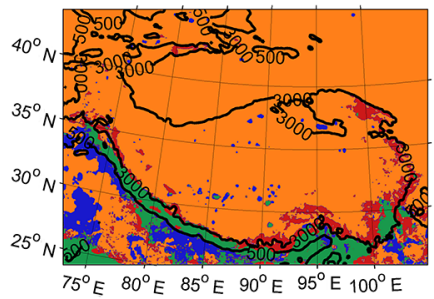

(f) F24H CONV

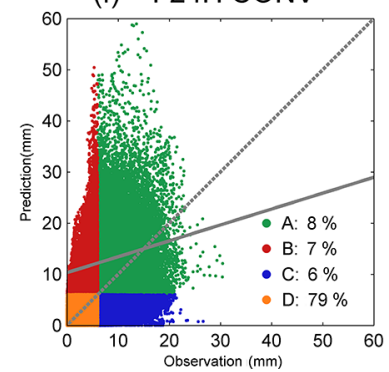

(c) F24H ATMS

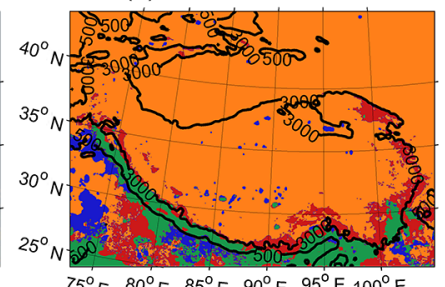

(g) F24H ATMS

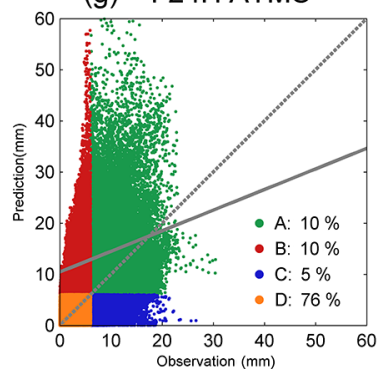

(d) $\mathrm{F} 24 \mathrm{H}$ CRIS

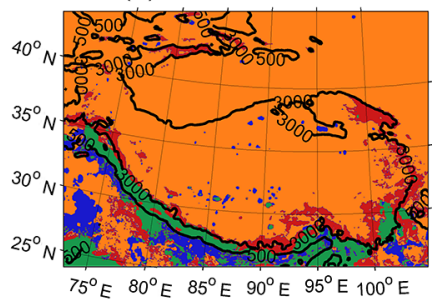

(h) F24H CRIS

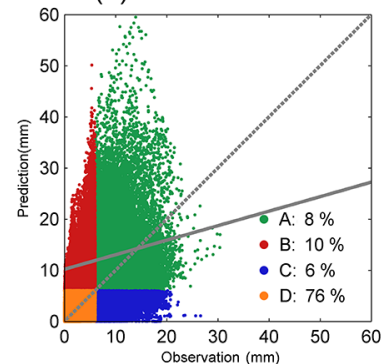

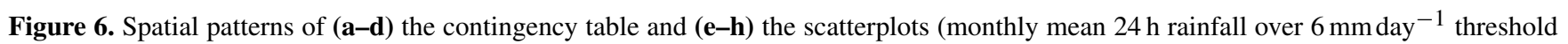
is defined as an "event"). A, B, C and D indicate the hits, false alarms, misses, and correct rejections in Table 2, respectively. The solid grey lines indicate the regression line of A. Black contours are altitude (unit: $\mathrm{m}$ ).

the hits and misses, similar to Fig. 5. Among the four linear regression lines (bold grey lines), ATMS looks a little better than the other three experiments but has more extremeprecipitation event forecasts than the others, followed by the CTRL and CRIS, while CONV has the lowest simulation precision. The high percentage $(\sim 84-89 \%)$ of hits and correct-rejection events indicates that rainfall events are well predicted. Furthermore, as the false alarms were primarily located in the east of the TP in contrast to the misses in the west, this special pattern can help improve WRF-ARW forecasts in the future, which means that the WRF-ARW model has promising potential in the TP area.

Figure 7 shows the monthly and domain average validation statistics in the TP. The differences between the four experiments for the $\mathrm{F} 24 \mathrm{H}$ forecasts are larger than for the $\mathrm{L} 24 \mathrm{H}$ forecasts. The ETS, FSS, and POD values all decline as the threshold increases; a higher value for these three skill scores indicates a better performance of the experiments. ATMS showed the highest FSS (Fig. 7b), ETS (Fig. 7c), and POD (Fig. 7d). CONV performed similar to the CTRL in ETS and FSS, and CRIS performed the worst. However, according to the BIAS, CONV is mostly approximately 1 , which indicates the best overall relative frequencies compared with the other experiments. Through the $1-5 \mathrm{~mm}$ threshold, CRIS performs the largest overforecast (BIAS $>1$ ), but it evolves to have a better performance than ATMS and CTRL through the 5-10 $\mathrm{mm}$ threshold. FAR and POFD results indicate that CONV performs best ( 0 is perfect), followed by ATMS and then CTRL and CRIS. However, POD results show that ATMS performs best ( 1 is perfect) and CONV is worst. The different statistics of forecast verification may depend on the purpose of the verification, and the results we evaluated by different methods can help answer the different questions of interest. Overall, the results reflect that DA has a positive effect on reproducing the monthly mean daily precipitation in the TP compared with CTRL to varying degrees.

\subsection{Impact of DA on the temporal distribution of precipitation forecast}

Another measure of performance is to examine how the daily precipitation is temporally distributed (Fig. 8). It can be seen in the time series of Fig. 8a that there are four observed heavy-rainfall events $\left(3.0 \mathrm{mmday}^{-1}\right)$ during the periods of $3-5,8-10,13-16$, and 22-25 July (Fig. 8a). In general, the $\mathrm{F} 24 \mathrm{H}$ amount of precipitation is overestimated in all three DA experiments by 20,40 , and $37 \%$ for CONV, ATMS, and CRIS, respectively. In contrast, of the four heavy-rainfall periods, three events - including 3-5, 13-16, and 22-25 July - are underestimated (grey shadings). The L24H forecasts (Fig. 8b) showed similar behavior, except that there were much smaller differences among the three DA experiments than in the F24H forecasts. In the F24H forecasts a 1-day time lag effect appears as compared with $\mathrm{L} 24 \mathrm{H}$, because the $\mathrm{F} 24 \mathrm{H}$ forecasts calculate the cumulative precipitation of the first 6-30 h, while the L24H forecasts represent the 30$54 \mathrm{~h}$ cumulative precipitation forecasts. When all the overestimation events are considered, the CONV (blue line) experiment captured the accumulated amount of precipitation much more accurately than the other DA experiments, and the ATMS (red line) performed the worst. It is usual to define the daily precipitation amounts $25.0-49.9 \mathrm{~mm}$ and $>50 \mathrm{~mm}$ as heavy rain and thunderstorm, respectively. However, due to the historical data sets of the TP indicating that the days of 

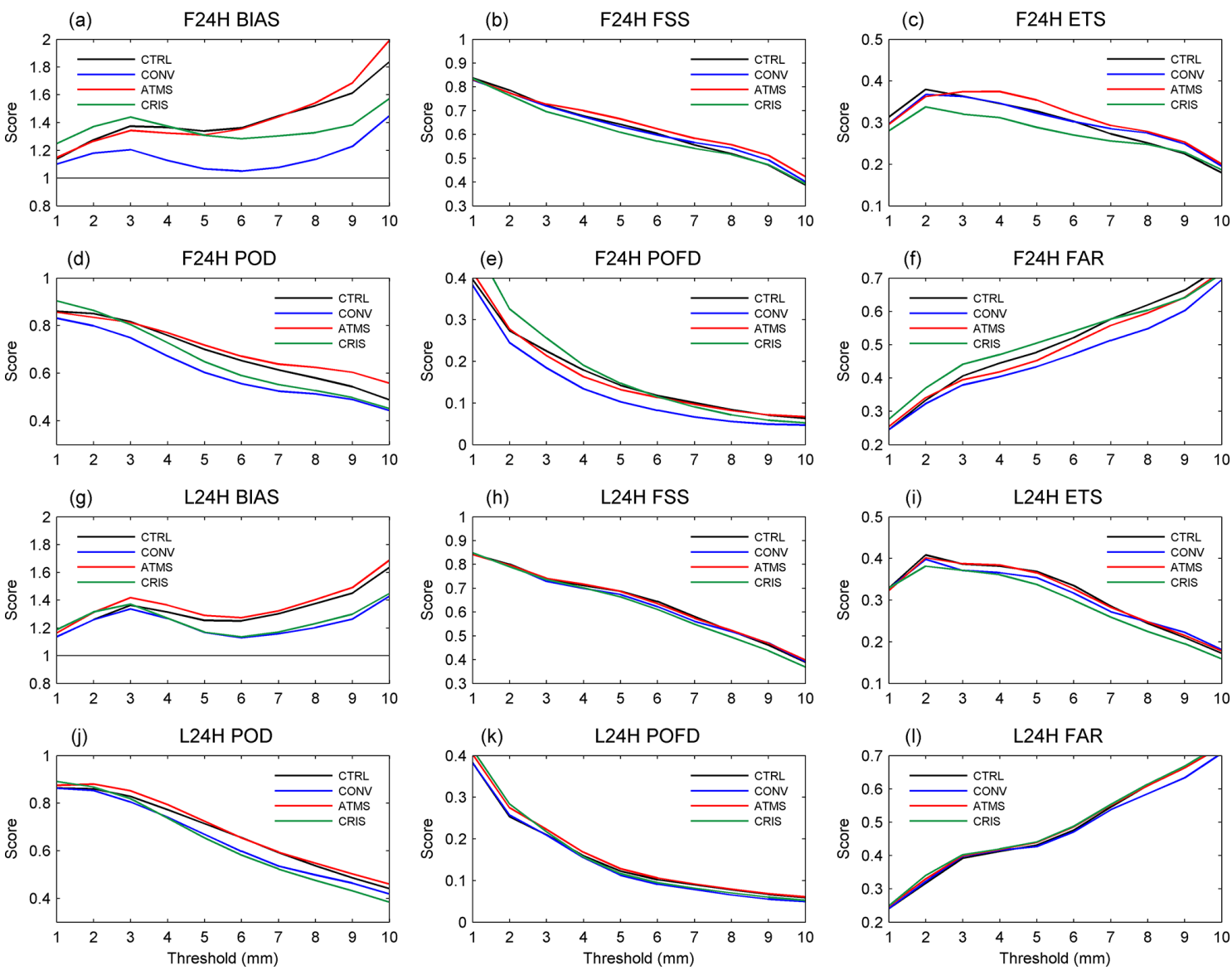

Figure 7. Monthly and domain average validation statistics for (a-f) F24H forecast and (g-l) L24H forecast. (a, g) are bias score; (b, h) are fraction skill score; $(\mathbf{c}, \mathbf{i})$ are equitable threat score; $(\mathbf{d}, \mathbf{j})$ are probability of detection; $(\mathrm{e}, \mathrm{k})$ are probability of false detection; (f, l) are false alarm ratio.
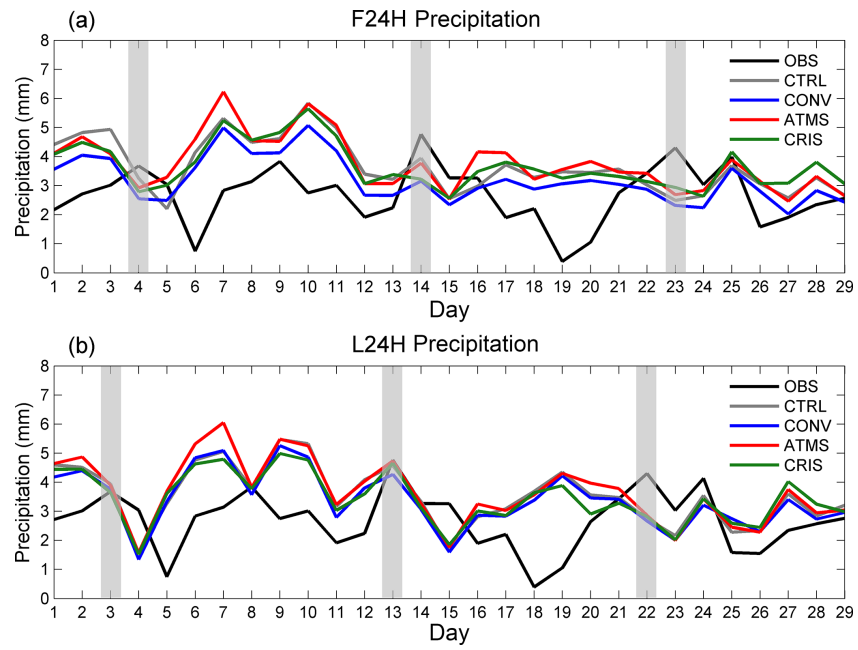

Figure 8. Time series of daily precipitation distribution for (a) F24H forecast and (b)L24H forecast. The black, grey, blue, red, and green lines indicate for observation, CTRL, CONV, ATMS, and CRIS, respectively. The unit is $\mathrm{mm}$. The grey shadings indicate the underestimated events. precipitation exceeding $50 \mathrm{~mm}$ are few (only accounting for $0.3 \%$ of rain days) (Wei et al., 2003) and referring to previous studies (Wang et al., 2011; Zhao et al., 2015), the heavyrainfall threshold was defined as above $20 \mathrm{~mm}$ for the $24 \mathrm{~h}$ precipitation in this study. As mentioned above, the $24 \mathrm{~h}$ precipitation maxima surpassing $20 \mathrm{~mm}$ are spread in the main precipitation region, showing that the prominent geographical dependence of rainfall coincides with the threshold of heavy rainfall defined for TP areas.

Although previous studies and our results show an obvious trend of overestimating rainfall in the TP, there appears to be underestimation during heavy-rainfall events (Fig. 8). To determine the forecast capabilities of the model in the heavyrainfall periods, we focused on the heavy-rainfall period of 3-5 July.

Figure 9 shows the rainfall intensities (bars) calculated for every $3 \mathrm{~h}$ amount of precipitation. The cumulative precipitation (curves) is defined as the precipitation accumulated during each $3 \mathrm{~h}$ period starting at 06:00 UTC during 3-6 July. From the perspective of observations, this rainfall event can be divided into three periods, of which 3 July 


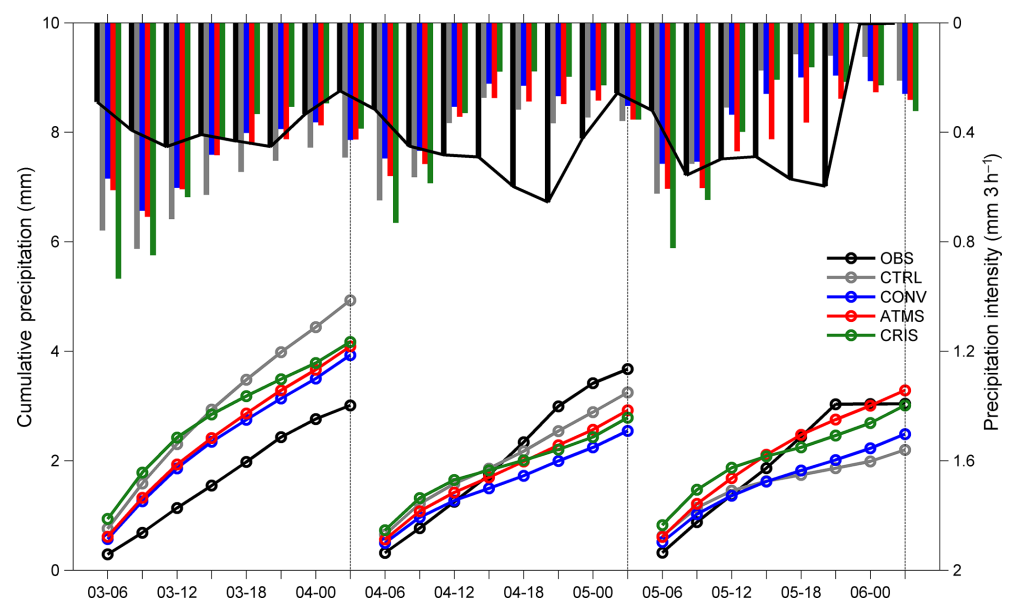

Figure 9. Rainfall intensities (bars) calculated for the amount of precipitation during each $3 \mathrm{~h}$ period. The cumulative precipitation (curves) is defined as the precipitation accumulated during each $3 \mathrm{~h}$ period starting at 06:00 UTC during 3-5 July. The unit is mm.

is ahead of the heavy rainfall with less than $0.45 \mathrm{~mm}$ per $3 \mathrm{~h}$, followed by the rainfall around 03:00 UTC on 4 July to 03:00 UTC on 5 July, with the first peak at 21:00 UTC on 4 July of more than $0.65 \mathrm{~mm}$ per $3 \mathrm{~h}$. The third phase started at 03:00 UTC on 5 July and ended at 00:00 UTC on 6 July, with a second rainfall pulse around 21:00 UTC on 5 July exceeding $0.60 \mathrm{~mm}$ per $3 \mathrm{~h}$ and then weakening. It is evident that this rainfall event had a significant diurnal harmonic, and the maximum precipitation always occurred at 18:00-21:00 UTC (00:00-03:00 LST). This diurnal variation was remarkable, especially when the heavy rainfall occurred, which was equivalent to evening local solar time (LST). However, the simulated maximum always occurred at 06:00-09:00 UTC (12:00-15:00 LST), earlier than the observations, and can probably be attributed to the limit of complicated topography. In this case, simulated rainfall intensity was much lower than the observations during 09:00 UTC on 4 July to 00:00 UTC on 5 July and 12:00 UTC on 5 July to 21:00 UTC on 5 July when the rainfall occurred. That is, the model cannot promptly quantitatively predict the sudden occurrence of this event. Moreover, the cumulative curves of the model show an overestimation on 3 and 5 July compared with observations; in particular, the cumulative curves of the CTRL are far away from the measured values due to an inaccurate initial field. It can be concluded that data from the DA experiments are closer to the observations during the heavyrainfall period than data from the CTRL experiment.

\subsection{Impact of DA on circulation and water vapor supply}

According to the abovementioned analysis, it is evident that DA improves forecasts during the heavy-rainfall period, but the results are not the same when different data sets are injected. As is well known, adequate water vapor transport is one of the preconditions for precipitation formation. In this section, we discuss the water vapor supply in the 3-5 July case study, with the aim of determining the reason for the different influences exerted by different experimental schemes. Figure 10 shows the F24H forecasts of precipitation quantity (shadings) and water vapor flux (vectors) during 3-5 July. Zonal components of wind velocity $(u)$, meridional component of wind velocity $(v)$, specific humidity $(q)$, and covariance, which are needed for flux computations, are provided at eight standard pressure levels $(1000,925,850,700,600$, 500,400 , and $300 \mathrm{hPa}$ ). The water vapor flux is integrated from the surface to the top of atmosphere (unit: $\mathrm{kg} \mathrm{m}^{-1} \mathrm{~s}^{-1}$ ) and averaged in time. The atmospheric water vapor flux can be written as

$$
\boldsymbol{Q}=Q_{\mathrm{u}} \boldsymbol{i}+Q_{\mathrm{v}} \boldsymbol{j}
$$

The zonal and meridional component of vapor flux is described by

$Q_{\mathrm{u}}=\frac{1}{g} \int_{p}^{P_{\mathrm{s}}} q u \mathrm{~d} p$

and

$Q_{\mathrm{v}}=\frac{1}{g} \int_{p}^{P_{\mathrm{s}}} q v \mathrm{~d} p$

where $P_{\mathrm{S}}$ is the surface level, $p$ is the top of atmosphere $(10 \mathrm{hPa})$, and $g$ is the gravitational constant $\left(9.8 \mathrm{~m} \mathrm{~s}^{-2}\right)$.

The water vapor flux divergence $\left(D\right.$, unit: $\left.\mathrm{kg} \mathrm{m}^{-2} \mathrm{~s}^{-1}\right)$ is given by

$D=\frac{\partial Q_{\mathrm{u}}}{a \cos \varphi \partial \sigma}+\frac{\partial Q_{\mathrm{v}}}{a \partial \varphi}$,

where $a$ is the radius of the model earth taken as $6371.2 \mathrm{~km}$, $\varphi$ is latitude in radians, and $\sigma$ is longitude in radians. 


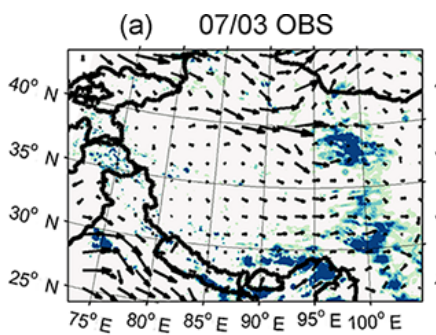

(d) $07 / 03$ CTRL

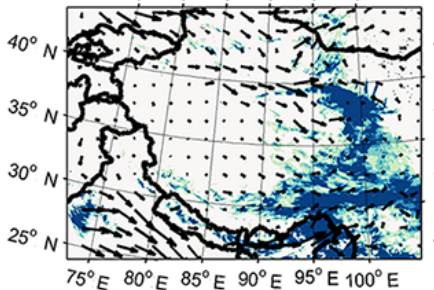

(g) $07 / 03$ CTRL-OBS

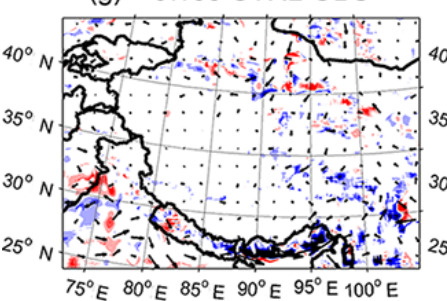

(b) $07 / 04$ OBS

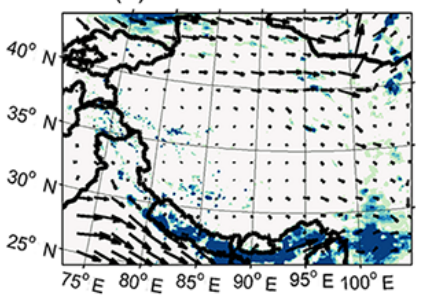

(e) $07 / 04 \mathrm{CTRL}$

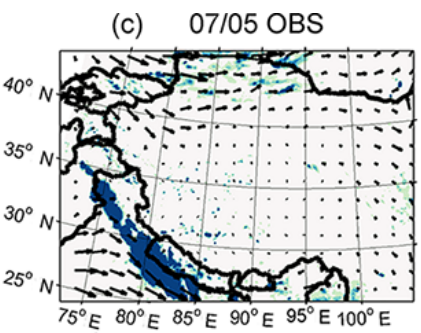

(f) $07 / 05 \mathrm{CTRL}$

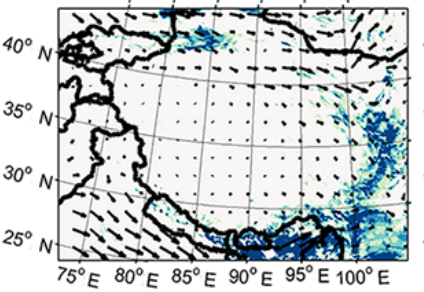

(h) $07 / 04$ CTRL-OBS

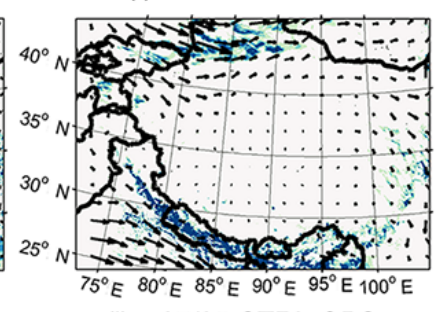

(i) $07 / 05$ CTRL-OBS
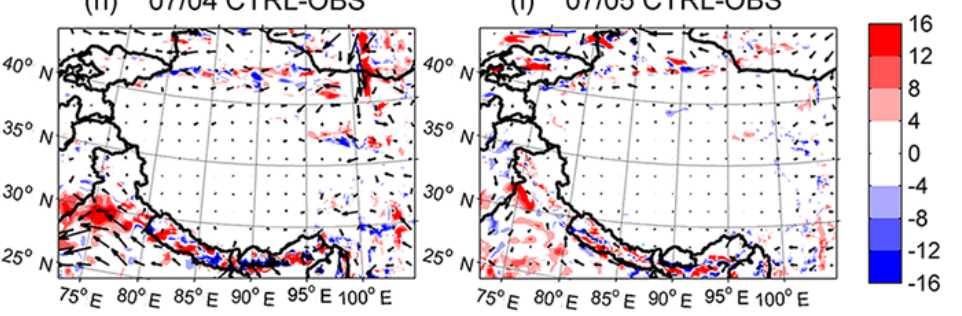

Figure 10. (a-f) F24H forecasts of precipitation (shadings) and water vapor flux (vectors) during 3-5 July for (a-c) OBS and (d-f) CTRL. (g-i) Differences in water vapor flux (vectors) and water vapor divergence (shadings) between CTRL and OBS. The unit of precipitation is $\mathrm{mm}$. The units for water vapor flux and divergence $\operatorname{are~} \mathrm{kg}(\mathrm{ms})^{-1}$ and $\mathrm{kg}\left(\mathrm{m}^{2} \mathrm{~s}\right)^{-1}$, respectively.

According to observations, warm and humid water vapor is transferred from the Bay of Bengal eastward by the southwest monsoon. The TP blocks the westward transport of humid and warm air, and this rainfall event starts developing in the southeast of the TP on 3 July; the rain belt runs southeast to southwest and develops along the Himalayas on 4-5 July. When the observations (Fig. 10a-c) are compared with model results (Fig. 10d-f), the simulated precipitation is considerably larger than the observed precipitation on 3 July before the heavy rainfall occurs, but as time goes on this condition reverses. For the difference value distribution (Fig. $10 \mathrm{~g}-\mathrm{i}$ ) of the CTRL minus observations, the main water vapor flux divergence differences (shadings) are negative in the rainy region on 3 July, which indicates that the water vapor convergence is stronger than observed, inducing the overestimation. However, when the rainfall event occurs on 4-5 July, this condition is opposite. The water vapor differences (vectors) also suggest that the observed water vapor conveyance from the southeast of the TP is larger than the model simulation, which induces inaccuracies in the forecast of the heavy rain. Therefore, analysis of moisture is useful for improving the heavy-rainfall forecasting skill.

To further discuss the effect of DA on this rainfall event, the differences between the simulated F24H precipitation and the observed distribution and the FSS skill scores
(Fig. 11) were considered. From the spatial distribution, all the experiments (Fig. 11a, d, g, j) overestimated the precipitation quantity, especially the CTRL, before the heavy rainfall, and the FSS skill scores all ranged from 0.46 to 0.49 with little differences (bottom left in Fig. $11 \mathrm{~m}$ ). When the heavy-rainfall event occurred on 4 July, the observed rain belt moved southwest (Fig. 11b, e, h, k), while the simulated rain belt was motionless, leading to an underestimation in the southwest. The FSS scores for ATMS, CONV, and CTRL ranged from 0.42 to 0.48 (middle in Fig. $11 \mathrm{~m}$ ), but CRIS only scored 0.36 . As the water vapor conveyance directly contributes to the westward movement of the rain belt and the intensity of this precipitation event on 5 July, the precipitation experiments all underestimated the amount of precipitation, and CRIS performed particularly badly (Fig. 10c, f, i). However, ATMS had a substantially high FSS scores (0.47) (right in Fig. $11 \mathrm{~m}$ ), followed by CRIS (0.45) and CONV (0.43), while CTRL only scored 0.35 . This result indicates that DA can indeed improve the heavy-rainfall forecast. From the above analysis of Figs. 9 and 11, it is clear that, before the heavy rainfall, DA can improve the simulation of precipitation spatially. As time passes and the heavy rainfall develops, DA, especially the ATMS assimilation, can enhance model prediction abilities both spatially and temporally in comparison with the CTRL experiment. 
(a) $07 / 03 \mathrm{CTRL}$

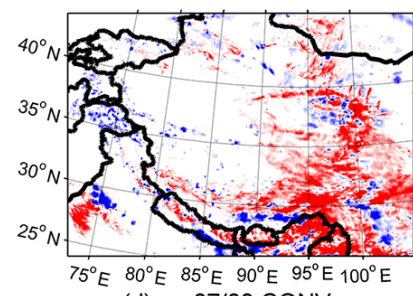

(d) 07/03 CONV

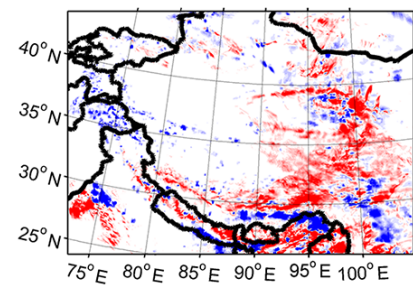

(g) 07/03 ATMS

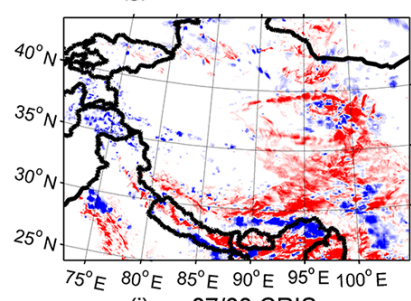

(j) $07 / 03$ CRIS

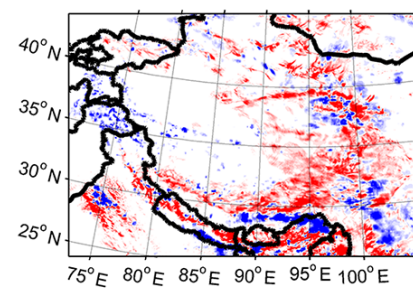

(m) FSS Score

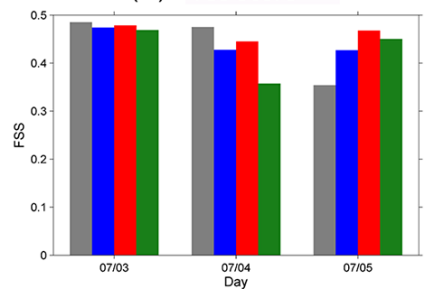

(b) $07 / 04$ CTRL

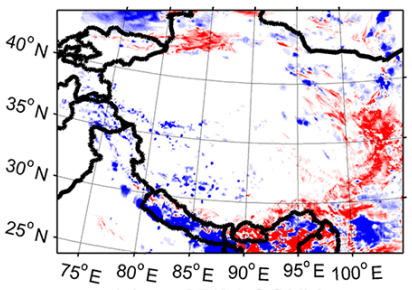

(e) $07 / 04$ CONV

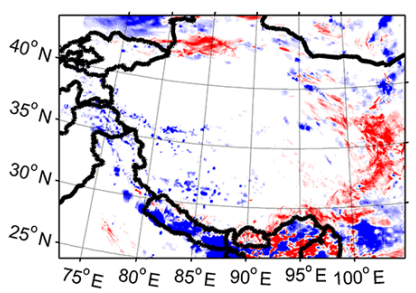

(h) $07 / 04$ ATMS

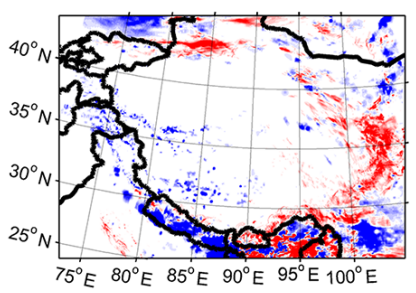

(k) $07 / 04 \mathrm{CRIS}$

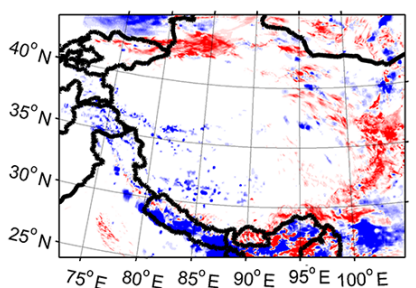

(c) $07 / 05 \mathrm{CTRL}$

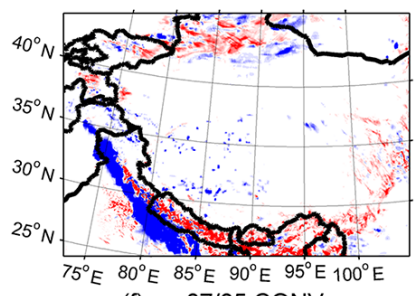

(f) $07 / 05 \mathrm{CONV}$

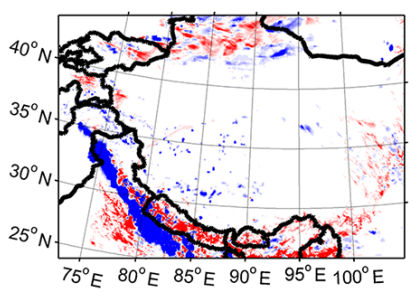

(i) $07 / 05$ ATMS

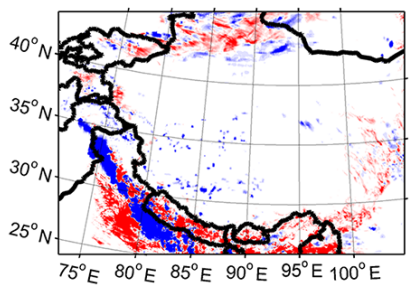

(I) $07 / 05$ CRIS

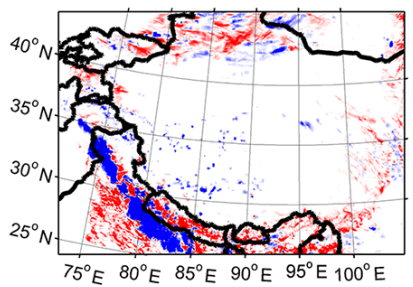

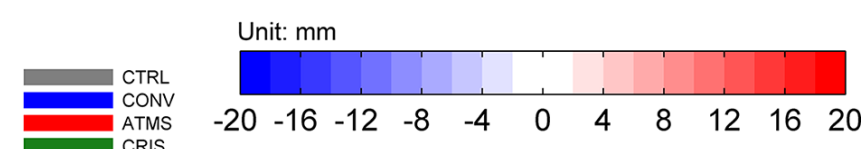

Figure 11. (a-l) are differences between the simulated F24H precipitation and the observed distribution, and (m) is the FSS skill scores with a $8 \mathrm{~mm} \mathrm{day}^{-1}$ threshold during 3-5 July. The unit of differences is $\mathrm{mm}$.

\section{Summary and discussion}

In this study, we used diagnostic methods to analyze the impact of DA on the monthly precipitation distribution over the TP and then focused on one heavy-rainfall case study that occurred from 3 to 5 July 2015. The DA and NWP were performed for July 2015 to make the weather forecasts. The spatial distribution of monthly mean precipitation showed an evident rain shadow effect along the Himalayas and that the precipitation decreased northward in the TP. However, the simulated precipitation belt was shifted northward compared with the observed rain belt and showed an orographic bias described as an overestimation upwind of the mountains and an underestimation in the south of the rain belt. Assimilation of satellite radiance also cannot calibrate the rain shadow effect, and all experiments showed consistently gross overestimation patterns. Furthermore, it seems that the rain shadow mainly influences prediction of the quantity of precipitation, but the main rainfall pattern can be well predicted. The pattern, in which false alarms are primarily predicted in the east of the TP and the misses in the west, indicates that the WRFARW model has promising potential to improve weather 
forecast ability. The DA validation statistics also suggest that DA has a positive effect on monthly mean precipitation prediction in the TP compared with the CTRL to varying degrees. For the time series of monthly precipitation, F24H and L24H precipitation chiefly overestimate the amount of precipitation, which is in agreement with previous studies, but the amount of $24 \mathrm{~h}$ precipitation in the three heavy-rainfall periods of 3-5, 13-16, and 22-25 July is underestimated.

To further study the underestimations in the heavy-rainfall events and the performance of the WRF-ARW model and GSI DA impact, we selected a case study from 3 to 5 July. It is evident that this rainfall event had a significant diurnal harmonic, and the maximum precipitation always occurred at 18:00-21:00 UTC (00:00-03:00 LST). This diurnal variation was remarkable, especially when the heavy rainfall occurred. Although the model cannot promptly quantitatively predict the sudden occurrence of this rainfall event, the DA, especially the ATMS simulation, is closer to the observations for the heavy-rainfall event than the CTRL experiments. Overall, before the heavy rainfall, DA improved the precipitation prediction spatially. As time passed and the rain belt moved and rainfall developed, DA enhanced the model prediction abilities both spatially and temporally. It should be mentioned that the high altitude and complex topography of the TP and its blocking effect on moisture transfer coming from Indian Ocean by the southwest monsoon obviously influence the rainfall forecast. As precipitation biases indicate some extent of spatial coherence and temporal recurrence, it is possible to provide an adapted correction method to enhance the model precipitation prediction capabilities.

It is conspicuous that the ATMS showed better performance than CTRL, CONV, and CRIS in the case study. Past studies have indicated that the effect of assimilation of both observations and satellite products is better than assimilation of satellite data only, which may account for the ATMS performing better than CONV. ATMS also performed better than CRIS. As clouds are opaque in the infrared wave band of the spectrum and largely transparent in the microwave band, microwave instruments are thought to perform better than infrared instruments on cloudy and rainy days, which may explain the better performance of ATMS than CRIS.

In this study, we investigated the monthly precipitation distribution and a selected heavy-rainfall case in the TP using the WRF-ARW mesoscale model and the GSI data assimilation system. Moisture and dynamic conditions were analyzed in the case study; however, thermal conditions are also one of the direct factors leading to rainfall that need to be investigated in the future.

Furthermore, although the CrIS assimilated large amounts of satellite radiance pixels, the general DA effect is relatively worse than in the other three experiments. CrIS has 1305 spectral channels, some of which are redundant as they include many satellite radiance observations from similar altitudes and contain much repeated information, which may lead to the poor DA impact. Priority should be given to se- lecting physical sensitivity and the high-vertical-resolution channels. Moreover, selecting channels is more difficult because of the high altitude, complicated dynamics, and thermal conditions. Therefore, only by carrying out further research on bias correction, quality control, and channel selection can satellite radiance data play an efficient role in TP weather forecasting.

In addition, model resolution and parameterized scheme selection are also key factors affecting forecast quality. In this study, the parameterized schemes we chose have been applied in previous studies of the TP. It would be worthwhile to make a comparative analysis of different parameterized schemes with higher model resolution in the future. Furthermore, it should be noted that, due to the heavy calculation burden, this study made use of 3D-Var as the assimilation method. Other advanced assimilation techniques - such as 4D-Var, hybrid, and EnKF - also need to be tested.

Data availability. ATMS and CrIS satellite radiance data are from the GDAS and in the BUFR format. All of this can be downloaded from https://www.ncdc.noaa.gov/data-access/model-data/ model-datasets/global-data-assimilation-system-gdas. NCEP Final Analysis data can be downloaded from https://rda.ucar.edu/datasets/ ds083.2/.

Competing interests. The authors declare that they have no conflict of interest.

Acknowledgements. The WRF-ARW model was obtained from NCAR, the GSI data assimilation system was obtained from JCSDA, and the satellite data sets were provided by NOAA/NESDIS/STAR. The authors are very grateful to these agencies for the models and for providing data. This work was jointly supported by the Special Fund for Public Welfare of the China Meteorological Administration (GYHY201406024) and the National Natural Science Foundation of China (91437104, 41130960). Jianjun Xu was supported by the National Innovation Project for Meteorological Science and Technology: Quality Control, Fusion, and Reanalysis of Meteorological Observations and the Guangdong Ocean University Research Funding of Air-Sea Interaction and Data Assimilation (300702/E16188). Tong Xue was a visiting scholar at GMU/AOES during this study and acknowledges helpful discussions with fellow members of GMU/AOES.

Edited by: Mark Kulie

Reviewed by: three anonymous referees 


\section{References}

Bormann, N., Fouilloux, A., and Bell, W.: Evaluation and assimilation of ATMS data in the ECMWF system, J. Geophys. Res.-Atmos., 118, 12970-12980, https://doi.org/10.1002/2013JD020325, 2013.

Chambon, P., Zhang, S. Q., Hou, A. Y., Zupanski, M., and Cheung, S.: Assessing the impact of preGPM microwave precipitation observations in the Goddard WRF ensemble data assimilation system, Q. J. Roy. Meteor. Soc., 140, 1219-1235, 2014.

Chen, Y., Ji, L., and Shen, R.: The numerical experiments on dynamic forcing by the Tibetan Plateau for various zonal flows, Adv. Atmos. Sci., 2, 189-199, 1985.

Derber, J. C. and Wu, W. S.: The use of TOVS cloud-cleared radiances in the NCEP SSI analysis system, Mon. Weather Rev., 126, 2287-2299, 1998.

Developmental Testbed Center: Gridpoint Statistical Interpolation Advanced User's Guide Version 3.5, 119 pp., available at: http: //www.dtcenter.org/com-GSI/users.v3.5/docs/index.php (last access: 14 July 2017), 2016.

Dong, P., Liu, J., Liu, G., and Huang, J.: Study on the assimilation of ATMS satellite data and comparison with AMSUA/MHS, J. Trop. Meteorol., 30, 623-632, 2014.

Eyre, J. R.: A bias correction scheme for simulated TOVS brightness temperatures, ECMWF, Reading, UK, Technical Memorandum, 186, 28 pp., 1992.

Gao, Y., Xu, J., and Chen, D.: Evaluation of WRF Mesoscale Climate Simulations over the Tibetan Plateau during 1979-2011, J. Climate, 28, 2823-2841, 2015.

Gao, Y. C. and Liu, M. F.: Evaluation of high-resolution satellite precipitation products using rain gauge observations over the Tibetan Plateau, Hydrol. Earth Syst. Sci., 17, 837-849, https://doi.org/10.5194/hess-17-837-2013, 2013.

Gauthier, P., Tanguay, M., Laroche, S., Pellerin, S., and Morneau, J.: Extension of 3DVAR to 4DVAR: Implementation of 4DVAR at the Meteorological Service of Canada, Mon. Weather Rev., 135, 2339-2354, 2007.

Guo, J., Zhai, P., Wu, L., Cribb, M., Li, Z., Ma, Z., Zhang, J.: Diurnal variation and the influential factors of precipitation from surface and satellite measurements in Tibet, Int. J. Climatol., 34, 2940-2956, 2014.

Han, Y., van Delst, P., Liu, Q., Weng, F., Yan, B., Treadon, R., and Derber, J.: JCSDA Community Radiative Transfer Model - Version 1 (CRTM-V1), NOAA Technical Report, 122, 40 pp., 2006.

He, Y., Yang, K., Yao, T., and He, J.: Numerical Simulation of a Heavy Precipitation in Qinghai-Xizang Plateau Based on WRF Model, Plateau Meteorology, 31, 1185-1186, 2012 (in Chinese).

Hubbard, K. G. and You, J.: Sensitivity analysis of quality assurance using the spatial regression approach-A case study of the maximum/minimum air temperature, J. Atmos. Ocean. Tech., 22, 1520-1530, 2005.

Jianyu Xu, Bing Zhang, Minghuan Wang, and Huijuan Wang: Diurnal variation of summer precipitation over the Tibetan Plateau: a cloud-resolving simulation, Ann. Geophys., 30, 1575-1586, https://doi.org/10.5194/angeo-30-1575-2012, 2012.

Kazumori, M.: Satellite radiance assimilation in the JMA operational mesoscale 4DVAR system, Mon. Weather Rev., 142, 1361-1381, 2014.

Liu, J., Bray, M., and Han, D.: A study on WRF radar data assimilation for hydrological rainfall prediction, Hydrol. Earth Syst.
Sci., 17, 3095-3110, https://doi.org/10.5194/hess-17-3095-2013, 2013.

Marteau, R., Richard, Y., Pohl, B., Smith, C. C., and Castel, T.: High-resolution rainfall variability simulated by the WRF RCM: application to eastern France, Clim. Dynam., 44, 1093-1107, 2015.

Massacand, A. C., Wernli, H., and Davies, H. C.: Heavy precipitation on the Alpine southside: An upper-level precursor, Geophys. Res. Lett., 25, 1435-1438, 1998.

Maussion, F., Scherer, D., Finkelnburg, R., Richters, J., Yang, W., and Yao, T.: WRF simulation of a precipitation event over the Tibetan Plateau, China - an assessment using remote sensing and ground observations, Hydrol. Earth Syst. Sci., 15, 1795-1817, https://doi.org/10.5194/hess-15-1795-2011, 2011.

National Centers for Environmental Prediction/National Weather Service/NOAA/US: Department of Commerce, 2008, updated daily, NCEP ADP Global Upper Air and Surface Weather Observations (PREPBUFR format), May 1997 - Continuing, Research Data Archive at the National Center for Atmospheric Research, Computational and Information Systems Laboratory, available at: http://rda.ucar.edu/datasets/ds337.0/ (last access: 18 July 2017), 2008.

Newman, K. M., Schwartz, C. S., Liu, Z., Shao, H., and Huang, X.-Y.: Evaluating Forecast Impact of Assimilating Microwave Humidity Sounder (MHS) Radiances with a Regional Ensemble Kalman Filter Data Assimilation System, Weather Forecast., 30, 964-983, 2015.

Pan, Y., Y. Shen, Q.-Q. Yu, and P. Zhao: Merged analyses of gaugesatellite hourly precipitation over China based on OI technique, Acta Meteorol. Sin, 70, 1381-1389, 2012 (in Chinese with English abstract).

Purser, R. J., Wu, W. S., Parrish, D. F., and Roberts, N. M: Numerical aspects of the application of recursive filters to variational statistical analysis. Part I: Spatially homogeneous and isotropic Gaussian covariances, Mon. Weather Rev., 131, 15241535, 2003a.

Purser, R. J., Wu, W. S., Parrish, D. F., and Roberts, N. M: Numerical aspects of the application of recursive filters to variational statistical analysis. Part II: Spatially inhomogeneous and anisotropic general covariances, Mon. Weather Rev., 131, 15361548, 2003b.

Roberts, N. M. and Lean, H. W.: Scale-selective verification of rainfall accumulations from high-resolution forecasts of convective events, Mon. Weather Rev., 136, 78-97, 2008.

Saunders, R., Matricardi, M., and Brunel, P.: An improved fast radiative transfer model for assimilation of satellite radiance observations, Q. J. Roy. Meteor. Soc., 125, 1407-1425, 1999.

Schwartz, C. S., Liu, Z., Chen, Y., and Huang X. Y.,: Impact of assimilating microwave radiances with a limited-area ensemble data assimilation system on forecasts of Typhoon Morakot, Weather Forecast., 27, 424-437, 2012.

Shen, Y., Zhao, P., Pan, Y., and Yu, J.: A high spatiotemporal gaugesatellite merged precipitation analysis over China, J. Geophys. Res.-Atmos., 119, 3063-3075, 2014.

Tong, K., Su, F., Yang, D., and Hao, Z. Evaluation of satellite precipitation retrievals and their potential utilities in hydrologic modeling over the tibetan plateau, J. Hydrol., 519, 423-437, 2014. 
Wang, C. H., Zhou, S. W., Tang, X. P., and Wu, P.: Temporal and spatial distribution of heavy precipitation over Tibetan Plateau in recent 48 years, Scientia Geographica Sinica, 31, 470-477, 2011.

Warner, T. T., Paterson, R. A., and Treadon, R. E.: A tutorial on lateral boundary conditions as a basic and potentially serious limitation to regional numerical weather prediction, B. Am. Meteorol. Soc., 78, 2599-2617, 1997.

Wei, Z., Huang, R. H., and Dong, W. J.: Interannual and interdecadal variations of air temperature and precipitation over the Tibetan Plateau, Chinese Journal of Atmospheric Sciences, 27, 157-170, 2003.

Weng, F.: Advances in radiative transfer modeling in support of satellite data assimilation, Hyperspectral Imaging and Sensing of the Environment 2009, Vancouver, Canada, 26-30 April 2009, Optical Society of America, paper HWD1, 2009.

Wu, W., Purser, R., and Parrish, D.: Three-Dimensional Variational Analysis with Spatially Inhomogeneous Covariances, Mon. Weather Rev., 130, 2905-2916, 2002.

$\mathrm{Xu}$, J., Rugg, S., Byerle, L., and Liu, Z.: Weather forecasts by the WRF-ARW model with the GSI data assimilation system in the complex terrain areas of southwest Asia, Weather Forecast., 24, 987-1008, 2009.

Ye, D. Z. and Gao, Y. X.: Tibetan Plateau Meteorology, Science, Beijing, 89-101, 1979.
Zapotocny, T. H., Jung, J. A., Le Marshall, J. F., and Treadon, R. E.: A two-season impact study of four satellite data types and rawinsonde data in the NCEP Global Data Assimilation System, Weather Forecast., 23, 80-100, 2008.

Zhang, X.-X., Bi, X.-Q., and Kong, X.-H.: Observed diurnal cycle of summer precipitation over South Asia and East Asia based on CMORPH and TRMM satellite data, Atmospheric and Oceanic Science Letters, 8, 201-207, 2015.

Zhao, X. Y., Wang, Y. R., Zhang, Q., and Luo, L.: Climatic characteristics of heavy precipitation events during summer half year over the Eastern Tibetan Plateau in recent 50 years, Arid Land Geography, 38, 675-683, 2015.

Zhu, F., Xu, G., and Li, L.: An assessment of the impact on precipitation prediction in the middle and lower reaches of the Yangtze River made by assimilating GPSPW data in the Tibetan Plateau, Chinese Journal of Atmospheric Sciences, 38, 171-189, 2014 (in Chinese).

Zou, X., Qin, Z. and Weng, F.: Improved coastal precipitation forecasts with direct assimilation of GOES-11/12 imager radiances, Mon. Weather Rev., 139, 3711-3729, 2011.

Zou, X., Qin, Z. and Weng, F.: Improved quantitative precipitation forecasts by MHS radiance data assimilation with a newly added cloud detection algorithm, Mon. Weather Rev., 141, 3203-3221, 2013. 